\title{
Novel Multimodal Interaction for Industrial Design
}

\author{
Bahar Sener, Owain Pedgley \\ Middle East Technical University \\ Turkey
}

\section{Introduction}

This chapter sets out the need to change the human-computer interaction (HCI) provided in digital tools for carrying out professional industrial design practice. Three-dimensional computer-aided design (3D CAD) has become an indispensable tool for industrial design, being the primary means for modelling and communicating product design proposals. However, a recurring complaint among industrial designers is that $3 \mathrm{D}$ CAD is too rooted in engineering design, and is directed towards neither their own creative practices for defining the form of a product (i.e. the activity of 'form creation') nor their underlying need for sketching (Shillito et al., 2003; Hummels, 2000).

The general concern in the literature is that the creatively intense early phase of industrial design, where the form of a product is in a conceptual and 'fluid' state, is very poorly supported. Presently only two systems are marketed as supporting conceptual form creation for industrial design: AliasStudio ${ }^{\mathrm{TM}}$ (Autodesk, 2008) and the FreeForm ${ }^{\circledR}$ virtual clay modelling system (SensAble Technologies Inc., 2008). The former makes good use of imported sketch elevation drawings and can be connected to a tablet PC to allow direct freehand drawing. The latter utilises haptic technology (force and kinaesthetic feedback) to harness designers' sense of touch, which is prominent during sketch modelling with workshop media such as Styrofoam ${ }^{\circledR}$ and clay.

It was against this backdrop of dissatisfaction that an empirical research programme was undertaken to identify and address the shortfalls of current 3D CAD systems used by industrial designers. The research programme had the aim of bridging gaps between current 3D CAD packages and envisioned systems specifically devised for industrial design practice. It addressed the research question: in what ways can digital design tools be enhanced or superseded to fit better to industrial designers' needs for conceptual form creation? Of concern was a need to examine in documentary detail what industrial designers liked and disliked about form creation in a variety of modelling media, and then to propose concepts for ways in which computers can - and could - provide improved support. It is worthwhile noting that conceptual design receives little attention in HCI literature, with the balance of research firmly on technical developments and system-specific 
evaluations. This is most surprising, given that matters of detail become largely academic if underlying or established concepts are found to be inadequate.

The primary motivation for the work was that until improved digital tools are realised, industrial designers will be resigned to adapt to 3D CAD essentially built for other professions (Sener et al., 2002; Hanna \& Barber, 2001). This does not seem to be a reasonable or sensible situation. Only through examination at a fundamental operational and conceptual level can the nature of inadequacies with 3D CAD for industrial design be revealed.

\section{Enaction, Cognitive Development Theories and CAD}

Before introducing the account of the empirical research, it is pertinent to provide a brief historical overview of the interplay of design modelling, human cognitive development theories and the evolution of CAD, up to and including state-of-the-art solutions. Historically, computer support for industrial design commenced with command-line 2D drafting and evolved from the 1980s into multimedia-driven 3D solid and surface modelling systems. It can be said that this transition has been from relatively crude to relatively sophisticated support. This comes as no surprise, since only through technological breakthroughs, which necessarily take time to develop and implement, does the opportunity arise for computer interaction to become more advanced and more sensitive to the needs of users. The idea of sophistication in CAD is an issue that demands closer inspection, and may be usefully illuminated by examining the human cognitive development theories of Piaget (1971) and Bruner (1966).

Piaget's theory involves three stages of cognitive transformation, commencing with sensorimotor representations (from simple reflexes to progressively controlled actions, for achieving effects in the world), through visual manipulations (drawing upon simple single representations to complex multiple representations), to fully matured formal operations (involving cognitive manipulation of complex symbolic systems). Each stage focuses on a new approach rather than an advancement of the preceding approach. Transition through each stage provides gradual clarity and depth of understanding making representations increasingly open to conscious and reflective manipulation ( $\mathrm{O}^{\prime}$ Malley and Fraser, 2004). Bruner's theory of intellectual development also involves three stages (enactive, iconic, and symbolic 'modes' or 'mentalities'), signifying transitions from implicit, tacit or sensori-motor representations to gradually more explicit representations (Figure 1).

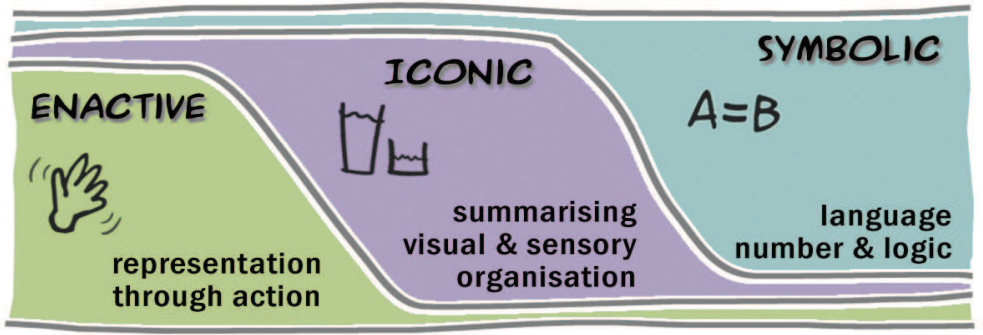

Fig. 1. Transition of learning according to Bruner 
Where Piaget's and Bruner's theories differ is that stage transitions are independent of domain or subject area for Piaget, whereas for Bruner each new domain of learning commences with the first stage of intellectual development, and is irrespective of age. The characteristics of Bruner's three cognitive development stages are described in Table 1.

\begin{tabular}{|l|l|}
\hline Enactive Mode & $\begin{array}{l}\text { Knowledge is generated and demonstrated through domain } \\
\text { activities: through learning by doing and the exercising of, and } \\
\text { reaction to, motor responses, especially in skilled physical activities } \\
\text { requiring dexterity and subtle exercising of, and reactions to, tacit } \\
\text { motor responses (e.g. typing, driving a car, dancing, playing a } \\
\text { musical instrument, crafting objects). }\end{array}$ \\
\hline Iconic Mode & $\begin{array}{l}\text { Knowledge about the domain generated in the enactive mode is } \\
\text { organised and structured. Knowledge is represented and } \\
\text { communicated primarily in the form of images. }\end{array}$ \\
\hline Symbolic Mode & $\begin{array}{l}\text { Rules are abstracted from the structure and inter-relations of } \\
\text { knowledge generated in the iconic mode. Knowledge is represented } \\
\text { and communicated as words, mathematical symbols and other } \\
\text { notation. }\end{array}$ \\
\hline
\end{tabular}

Table 1. Bruner's three modes of cognitive development

Kay, the visionary who created the object oriented software language Smalltalk, has offered the insightful slogan 'DOING with IMAGES makes SYMBOLS', as a theoretical underpinning for HCI (Kay, 1987; 1996). The slogan directly relates HCI to Piaget's 'stage model' and Bruner's 'mentalities model' (Figure 2). Kay's slogan implies (as did Bruner) that to be compliant with cognitive development theory, the design of HCI should commence with, and be grounded in, 'DOING with IMAGES', and only then be carried into the more abstract 'makes SYMBOLS'. In reality, the opposite progression has been the case, owing to the technological and conceptual difficulties of creating computer systems that operate in an enactive mode (Verplank, 2003).

CAD development reality

\section{DOING with IMAGES makes SYMBOLS}

\begin{tabular}{llll}
\hline $\begin{array}{l}\text { Piaget's } \\
\text { stages }\end{array}$ & $\begin{array}{l}\text { kinesthetic/ } \\
\text { sensorimotoric }\end{array} \quad$ visual & symbolic / formal
\end{tabular}

$\begin{aligned} & \text { Bruner's } \\ & \text { mentalities }\end{aligned}$ enactive iconic symbolic

Kay's principles know where you are, recognise, compare tie together long chains
for interface design manipulate configure, concrete of reasoning, abstract

Fig. 2. Human cognitive development versus history of CAD development 
So what relevance does the pursuit of enactive interfaces have for computer support for industrial design? The answer is that enactive modes of operation are at the core of industrial designers' designing-and-making and pen-and-paper sketching activities (Sener, 2007). Thus support for enaction can be considered a natural, immediate and intuitive means of $\mathrm{HCI}$ for industrial design. Currently only one commercial 3D CAD system is built around an enactive interaction: the aforementioned FreeForm ${ }^{\circledR}$ system. As with other enactive interfaces, FreeForm ${ }^{\circledR}$ delivers multimodal HCI through dual attention to the software and the physical devices that allow access to, and manipulation of, virtual objects (O'Malley and Fraser, 2004; Sener and Pedgley, 2005).

Whilst FreeForm ${ }^{\circledR}$ is a commercially successful product, most enactive interfaces for professional applications are at a pre-commercialisation stage (European Enactive Network of Excellence, 2008). For example, software and hardware developers within research organisations are currently showing how enactive interfaces that integrate a combination of visual technologies (e.g. virtual reality, immersion, holography) and spatial/dynamic technologies (e.g. haptic interaction, tactile interaction, kinaesthetic interaction, gestural sketching) can have application in design disciplines (Bordegoni and Cugini, 2006).

Overall, the implementation of enactive interfaces within 3D CAD is still at a very early stage, largely as a result of technical limitations and the previously mentioned legacy in which HCI for 3D CAD has developed from a starting point of text-based instructions. FreeForm ${ }^{\circledR}$, for example, still relies on considerable CAD-like command interaction (i.e. menus, keyboard input, mouse actions) to accompany its haptic capabilities.

\section{Research Methodology}

The kinds of structure and interaction that digital industrial design tools will possess in the future is not a subject frequently visited in the literature. Furthermore, reports of empirical research into industrial designers' form creation activities are also relatively sparse. As a general observation, previous studies have failed to examine in detail the comparative strengths and weaknesses of the various modelling media designers use, instead concentrating in the main on modelling technique and good practice - often for just one modelling medium. This situation is not so surprising, since to generate empirical evidence that exposes designers' general form creation needs, rather than their perceived needs or scattered and generalised anecdotal evidence, requires considerable effort. Generation of this evidence base across modelling media was deemed a vital first step for ensuring the credibility of any new HCI concepts for 3D CAD.

The research programme therefore commenced with a substantial documentary study of industrial designers' form creation activities with two established media (Styrofoam ${ }^{\circledR}$, conventional CAD) and one state-of-the-art medium (FreeForm ${ }^{\circledR}$ ). The study comprised a series of 40 design and modelling experiment sessions, each lasting approximately two hours, conducted with a total of 16 UK-based participants. The participants were split into two groups of 8 participants each. Group 1 spanned employed, freelance, university staff and postgraduate industrial designers. Group 1 participants were involved in experiments covering all three media (24 sessions in total). Group 2 comprised solely industrial design undergraduates, who were involved in experiments covering only Styrofoam ${ }^{\circledR}$ and 
conventional CAD (16 sessions in total). A variety of 3D CAD systems were used (3DStudio Max, AutoCAD, I-DEAS, Lightwave 3D, Mechanical Desktop, Pro/Engineer, Rhinoceros, SolidWorks) - these being the participants' preferred and familiar systems.

Each session involved a participant creating the form for a small-sized household item (perfume container or salt and pepper shaker) or consumer electrical product (computer mouse or computer speakers) using just one modelling medium. To limit any order effect, the participants worked on different products for each modelling medium, thereby reducing the likelihood of transferring experiences from one session to another. In addition, each participant completed a mood adjective checklist before and after each session (Mackay et al., 1978). The evaluation of the checklist revealed no experiment conditioning and no order effects between the various combinations of sessions and modelling media. The participants were free to use pen and paper sketching during the sessions.

Real-time data were generated through video recording and researcher observation, and were accompanied by questionnaires completed by the participants during the sessions, which gauged the participants' first-hand experiences of modelling. A review interview was held at the end of each session to provide an opportunity to clarify any element of the generated data, and to allow participants an opportunity to volunteer further insights into their modelling. As far as is known, the experiments comprised the first major comparative study of 3D sketch modelling in industrial design.

A full account of the data collection, code-based processing and analysis would be too lengthy for inclusion here, so readers are referred to its primary documentation (Sener, 2004). The data originating from the questionnaires and review interviews comprised approximately 800 individual statements on the strengths and weaknesses of modelling with Styrofoam ${ }^{\circledR}$, conventional CAD and FreeForm ${ }^{\circledR}$. A hybrid strengths - weaknesses opportunities - threats (SWOT) analysis, based on guidelines by Ulrich \& Eppinger (1995), was followed to translate the strength and weakness statements into a set of customer need statements for improved digital industrial design tools. Briefly, this involved collating and consolidating the collective strengths across the three modelling media and redressing (i.e. reversing the expressed negativity) of the collective weaknesses. Figure 3 contains the definitive set of customer need statements. The processing procedure determined a priority position for each customer need statement, so that Figure 3 presents the statements in priority order from the especially important at the head to the moderately important at the foot. The terms 'quick', 'easy' and 'good' were merged during the data processing because participants used them interchangeably.

Figure 3 can be regarded as an explicit guide to desirable specifications for digital industrial design tools and their associated HCI. Four key themes can be identified.

Bulk/sketch form creation. The highest priority customer need statement quick/easy/good basic form creation - refers to sketching of product form in a proportionally correct and simplified manner free of constraints and dimensions.

Control of form creation. Seven customer need statements pointed to controlled form creation: constrainable tools, constrained form creation, precise, quick/easy/good detailing, quick/easy/good attribute control, and quick/easy/good uniform surface finish/texture. 
Ease of form creation. Six customer need statements pointed to minimal effort and removing obstacles in creating form: user-friendly interfaces, useful variety of modelling tools, high proficiency with minimal practice, form creation guidance, form construction aids, and comfortable input devices.

Life-like form creation. Five customer need statements pointed to replicating the multimodal sensory experience of creating physical models: life-like model appearance, lifelike tool/material contact, model interaction with hands, haptic feedback, and tools analogous to workshop tools.

\begin{tabular}{|r|l|}
\hline$\#$ & Customer need \\
\hline 1 & quick/easy/good basic form creation \\
\hline 2 & model interaction with hands \\
\hline 3 & precise \\
\hline 4 & quick/easy/good uniform surface \\
\hline 5 & haptic feedback \\
\hline 6 & quick/easy/good form detailing \\
\hline 7 & quick/easy/good form attribute control \\
\hline 8 & unlimited model viewpoints \\
\hline 9 & quick/easy/good curvy form creation \\
\hline 10 & quick/easy/good shape/form modification \\
\hline 11 & life-like model appearance \\
\hline 12 & life-like tool/material contact \\
\hline 13 & reversible \\
\hline 14 & user-friendly interface \\
\hline 15 & form creation guidance \\
\hline 16 & useful variety of modelling tools \\
\hline 17 & form construction aids \\
\hline 18 & comfortable input devices \\
\hline 19 & high proficiency with minimal practice \\
\hline 20 & quick/easy/good form visualisation \\
\hline 21 & constrainable tools \\
\hline 22 & multiple/interchangeable input devices \\
\hline 23 & reasonable workload on left \& right hands \\
\hline 24 & suitable for product design \\
\hline 25 & tools analogous to workshop tools \\
\hline 26 & quick/easy/good model export \\
\hline 27 & manufacturable output \\
\hline 28 & size/proportion feedback \\
\hline 29 & quick/easy/good model spatial arrangement \\
\hline 30 & constrained form creation \\
\hline
\end{tabular}

Fig. 3. Prioritised customer needs for improved digital industrial design tools

The first two of these themes are clearly in tension. Thus, the results showed that the absence of convincing digital sketching provision, and in particular a lack of marriage between sketch form creation and constrained form creation, in both 2D and 3D modelling environments, is a major issue to be redressed in the design of $3 \mathrm{D}$ CAD systems for industrial designers. The combination remains elusive in currently available systems. 


\section{4. $\mathrm{HCl}$ Design}

\subsection{Ideation}

As is normal, the customer need statements fall short of providing ideas for tangible HCI solutions: they point to issues to be resolved, but not how they can be resolved. It is only through creative input - designing - that customer needs can be acted upon and design ideas proposed. It was therefore essential to integrate a design project into the research programme so that the customer need statements could be translated into envisaged new $3 \mathrm{D}$ CAD systems. This was achieved during a period of practice-led design research (Arts and Humanities Research Council, 2007; Pedgley \& Wormald, 2007).

The designing was undertaken by the first author, a trained industrial designer, who drew upon a variety of specific experiences and sources of information to assist in ideation. The major inputs were: (i) the set of 30 customer needs in Figure 3, (ii) the prior art reviews concerning the history of 3D CAD development, and (iii) a four month industrial placement at Procter \& Gamble Technical Centres UK. During the placement, the author was employed to design, model, and prototype new consumer goods using the FreeForm ${ }^{\circledR}$ system. As a practising designer in Procter \& Gamble, she had significant professional authority for her investigations of how 3D CAD was perceived and used by other designers. Her involvement in the day-to-day business of the company's NPD programmes provided evidence of the uses of 3D CAD that otherwise would have been impossible to obtain. It also allowed for an effectiveness evaluation of 3D CAD driven by haptic interfaces, within a commercial context.

Other inspiration to aid the designing came from wider reading in the crossovers between communication technologies and contemporary product design, as well as personal experiences of 3D sketch modelling in a variety of media. Specific sources included Philips' Vision of the Future (Philips Design, 1996) and several Hollywood sci-fi movies including Minority Report, The Matrix Trilogy, and The World Is Not Enough.

\subsection{User Participation}

The purpose of involving target end users in the design project was to share ideas, create synergies and generally enrich the design activity and outcomes. Six participants were recruited from amongst the pool of eight within group 1 of the design and modelling experiments. All of the participants therefore possessed a heightened awareness of the research aims and had first-hand experience of state-of-the-art modelling through their FreeForm ${ }^{\circledR}$ sessions.

The first author assumed the role of facilitator and note taker during two three-hour sessions with users. The first session focused on generating individual ideas for new kinds of form creation tools and environments. It was explicitly stated that acceptable ideas could be either incremental improvements to existing technologies or 'future-gazing' solutions. The set of customer need statements was provided as a stimulus. The second session employed scenario building (Hasdogan, 1997) to elicit ideas on how individual ideas could be combined.

The participants communicated their proposals through A2 sketch sheets and verbal reports. Following the sessions, the proposals were examined for common features, which 
were then visually or verbally grouped under keyword headings. The proposals showed a general desire for designers to work within more dedicated, customisable surroundings enhanced by digital technologies.

\subsection{Concept Development}

Concept development continued as a solo effort by the first author. Two strands identified from the user participation sessions were adopted to aid the process: 'workspace concepts' (broadly referring to digitally enhanced environments for industrial designers to work in) and 'form creation concepts' (broadly referring to new HCI for industrial designers to digitally define product form). The separation is acknowledged to be forced, particularly since with technologies such as immersive virtual reality (VR), as far as users are concerned the 'workspace' becomes almost imperceptible and the 'form creation' dominates. The separation was nonetheless helpful in directing the emerging design ideas and communicating the final concepts.

A balance was sought between concepts that were immediately realisable (and that suggested incremental improvements to, and combinations of, existing technologies), and those that would require technology to advance. Special attention was paid towards developing concepts that offered plausible new routes for digitally sketching product form, especially through multimodal interactions. In all cases, the concepts were required to be coherent in the sense that they combined individual ideas into a convincing system. It was an explicit objective to satisfy the highest number of customer need statements as practically possible, although readers will appreciate that not all customer needs could be satisfied within a single concept without that concept becoming too incoherent. Matrices were used to check the compliance of each concept against the 30 customer need statements.

A portfolio containing eleven individual concepts was prepared: four workspace concepts and seven form creation concepts. A name was assigned to each concept and a text description of the essence of the concept was written. The concepts were prepared as presentation-quality colour illustrations in a purposefully 'cartoon style'. The style choice was important: it was chosen to promote flexibility in interpretation, rather than finality in specification that would accompany a photorealistic rendering or physical mock-up.

\section{Concept Portfolio}

\subsection{Workspace Concepts}

WC1 'Desktop Computing' enhances the sensory information experienced by designers within a contemporary desk environment, utilising multiple and interchangeable input devices connected to large flat screen displays, including haptic devices and stereovision glasses.

The idea behind WC2 'Immersive Room' is to set an immersive theme and mood within a dedicated collaborative workroom, in a similar way to desktop themes and wallpaper in Microsoft Windows or Mac OS. The environment can be instantaneously switched from project to project, with full-scale projections of, for example, CAD software, moodboards, competitor products and products in use. The workspace is used in conjunction with wireless tablet PCs and optional haptic gloves and stereovision glasses. Designers are free to sit or stand. 
The technology embodied in WC3 'Intelligent Screens' allows designers to move away from desktop cubicles towards open-plan environments that facilitate collaboration and sharing of information. Touch screens and finger-based haptic devices allowing two-handed interaction are prominent. Programmable finger thimbles are used to perform various functions with the touch screens. To aid collaboration, design updates can be wirelessly streamed between designers, and the screens can operate in either single-sided mode (opaque) or double-sided mode (transparent) to further strengthen collaboration. Designers are free to sit or stand and can communicate via an audio link.

The idea behind WC4 'Advanced Wireless Virtual Reality' is a fully programmable VR system based on non-invasive technology that is wireless, miniaturised and lightweight. It represents a technological progression of current VR and haptic applications within a dedicated workroom. Programmable VR software is customised to designers' preferences and is coupled to multiple and interchangeable peripherals (e.g. motion-trackers, wireless haptic fingertip sensors, stereovision headset, foot control sensors, voice command receivers). The concept allows two-handed interaction, full-scale model evaluation, and collaborative working through shared VR information. Figure 4 shows WC1 to WC4.
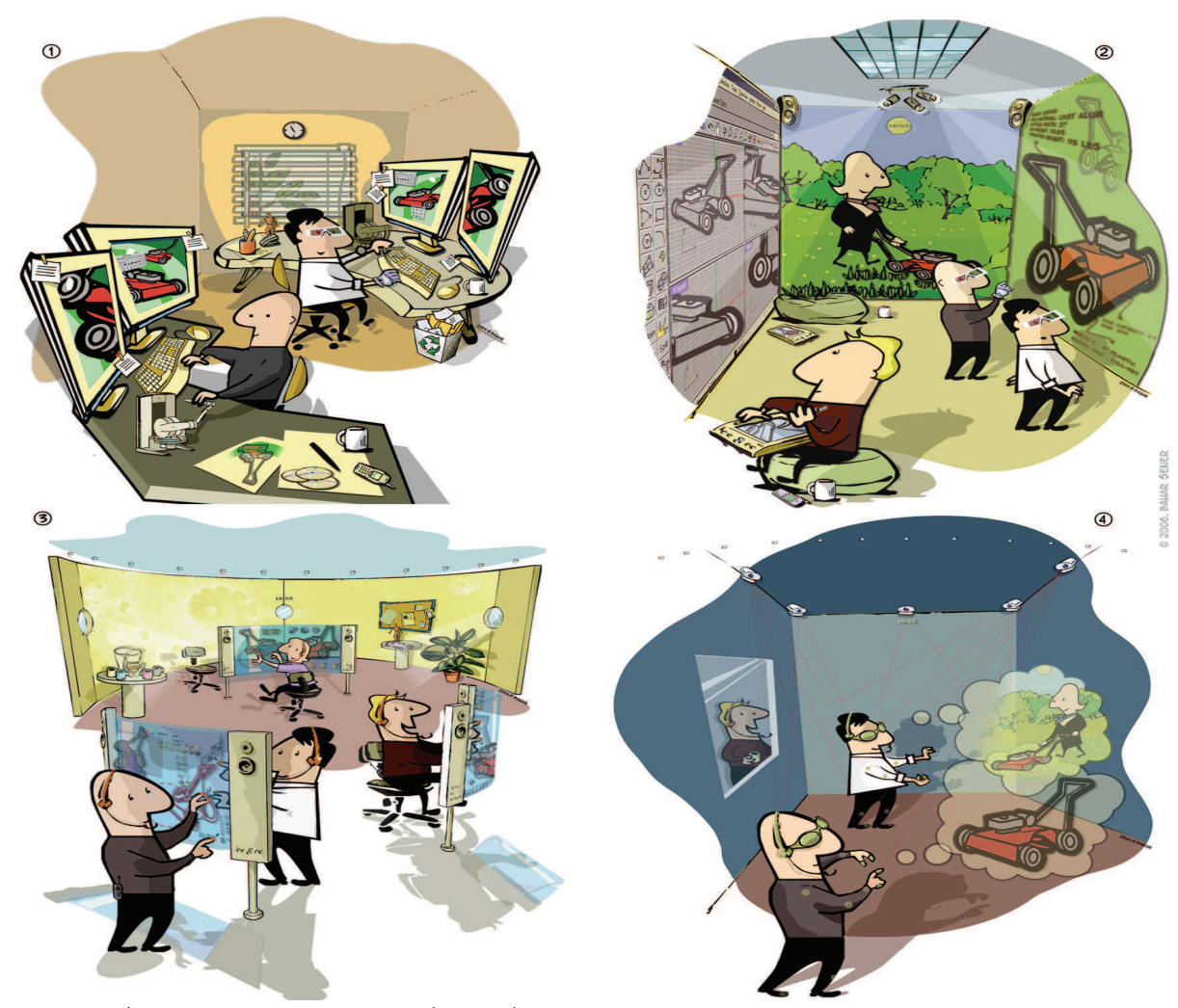

Fig. 4. Workspace concepts WC1 through to WC4 


\subsection{Form Creation Concepts}

Two-handed haptic feedback is the essential feature of FC1 'Dual Co-Located Haptic Devices', which combines elements of the FreeForm ${ }^{\circledR}$ system with bespoke hardware manufactured by Reachin Technologies AB (2008). The latter comprises a monitor that displays a CAD model stereoscopically and 'in mirror image' so that when viewed on a reflective screen the model appears convincingly in 3D and in correct orientation. Thus, the on-screen cursor (modelling tool) controlled by the FreeForm ${ }^{\circledR}$ input device (Phantom ${ }^{\circledR}$ ) is co-located (handeye coordinated) with the physical nib position of the Phantom ${ }^{\circledR}$. This concept specifically addresses the absence of two-handed control and realistic movement within present haptic systems. One hand is intended to grasp the model (using a haptic glove), whilst the other is intended to shape the material (using the Phantom ${ }^{\circledR}$ ). The palette of modelling tools could be for any virtual material, although Styrofoam ${ }^{\circledR}$ and clay are most suited to industrial design. Tools ranging from delicate hand tools to large machine tools would be recreated digitally.

The intention behind FC2 'Smart Material' is to make form creation with digital tools as interactive and spatially unconstrained as the manual shaping of workshop materials. It relies on the use of malleable material impregnated with particles that can be continuously position-detected in 3D space, allowing a digital equivalent of designing-and-making.

FC3 'Haptic Holographic Representation' uses a form of non-physical rapid prototyping, allowing visual, haptic and 'walk around' evaluation of an emerging product form projected holographically from a pod. It is an entirely waste-free and instantaneous system, independent of modelling software, and is intended to assist form modifications in real-time and promote collaborative product evaluation between remote sites. Optional stereovision glasses and haptic finger thimbles are used to allow enhanced multimodal evaluation.

The premise behind FC4 'Sequential Scanning' is that organic and texturised forms are easy to create in non-digital media (e.g. Styrofoam ${ }^{\circledR}$, clay). The concept builds upon this and includes intelligent reverse engineering software to automatically create high-quality editable surface models (i.e. constructed from splines, arcs, circles, lines etc.) from point cloud scan data of pre-modelled forms.

FC5 'Squidgy Sponge' is a highly interactive wireless input device that can be manipulated and deformed in $3 \mathrm{D}$, with the resulting deformations mapped onto selected areas of a digital model in real-time. The device can be twisted, indented, squeezed, tapered, stretched, squashed, folded etc. The device can also be deformed by pressing a physical object into it.

FC6 'Verbal/Gestural Input' extends the application of gestural sketching (Hummels, 2000), in which the movement of one's hands, arms or head becomes a tool for sketching, and in so doing overcomes spatial and functional limitations of 2D (planar) movement associated with pen and paper sketching. At its heart is personal expression, allowing designers to 'act out' and 'talk through' their ideas for product form. The system uses motion trackers and microphones to capture input data, whilst stereovision glasses may be optionally worn.

The familiarity of paper-based sketching is harnessed in FC7 'Automated 2D-to-3D Translation' and augmented by intelligent software to create 'clean' model geometry and a 
correspondingly high-quality surface model. The software shows in real-time how a product sketched in 2D elevations on a tablet PC will appear as a 3D form. This concept takes influences from sketch mapping (Tovey, 2002) and proven methods of 2D-to-3D translation (Igarashi \& Hughes, 2003) and represents an attempt to harness and surpass functional and qualitative aspects of paper-based sketching. It is intended to relieve designers of the relatively mundane task of 3D CAD geometry construction. Figure 5 shows FC1 to FC7.

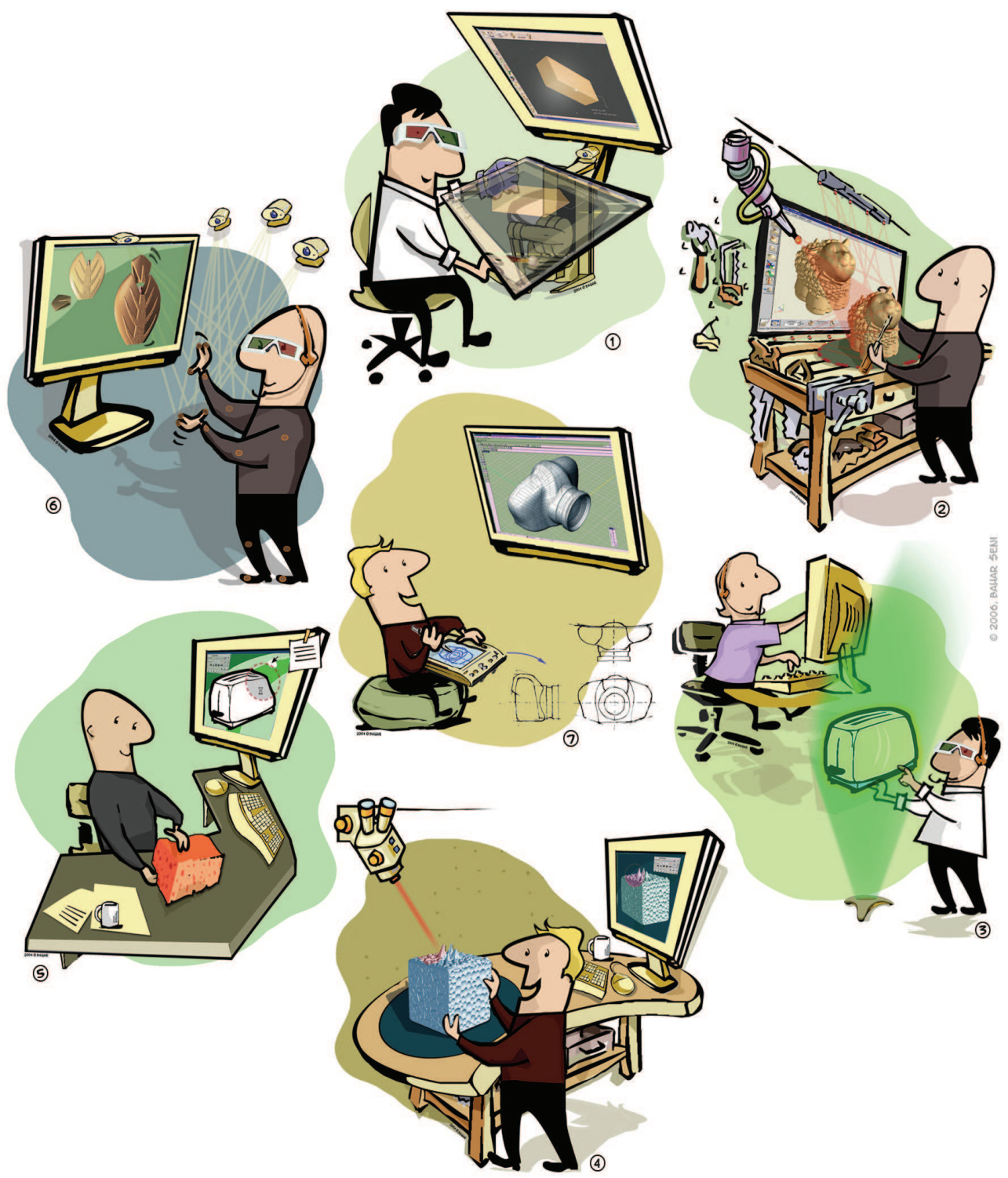

Fig. 5. Form creation concepts FC1 through to FC7 


\section{Evaluation Method}

The evaluation of the concepts was carried out through a questionnaire distributed to ten participants: the same eight participants of group 1 in the design and modelling experiments, and two additional staff industrial designers at Loughborough University. A $100 \%$ return rate was achieved. The participants were chosen because collectively they represented an 'elite group' of especially well informed designers, having had significant prior involvement in the research. They had also demonstrated proficiency in Styrofoam ${ }^{\circledR}$ and 3D CAD and had practical experience with FreeForm ${ }^{\circledR}$. The continued involvement of the same participants was viewed positively and was expected to lead to particularly critical evaluation of the concepts.

A questionnaire was chosen over individual interviews to allow the participants to pace themselves during their evaluations and to create a standardised set of data (Jorgensen, 1989). The overall aim was to identify the most favoured and least favoured concepts, and to identify the features and characters of those concepts that led to their particularly supportive or unsupportive evaluation. Each concept was requested to be evaluated individually against three principal criteria: enjoyment, inspiration and assistance. When combined, these three criteria were intended to create a good assessment of the overall desirability of the concepts as measured by long-term use (enjoyment), stimulation for design ideas (inspiration) and utilitarian benefits (assistance). Figure 6 shows the questionnaire template and the use of Likert scale statements to elicit participants' reactions.

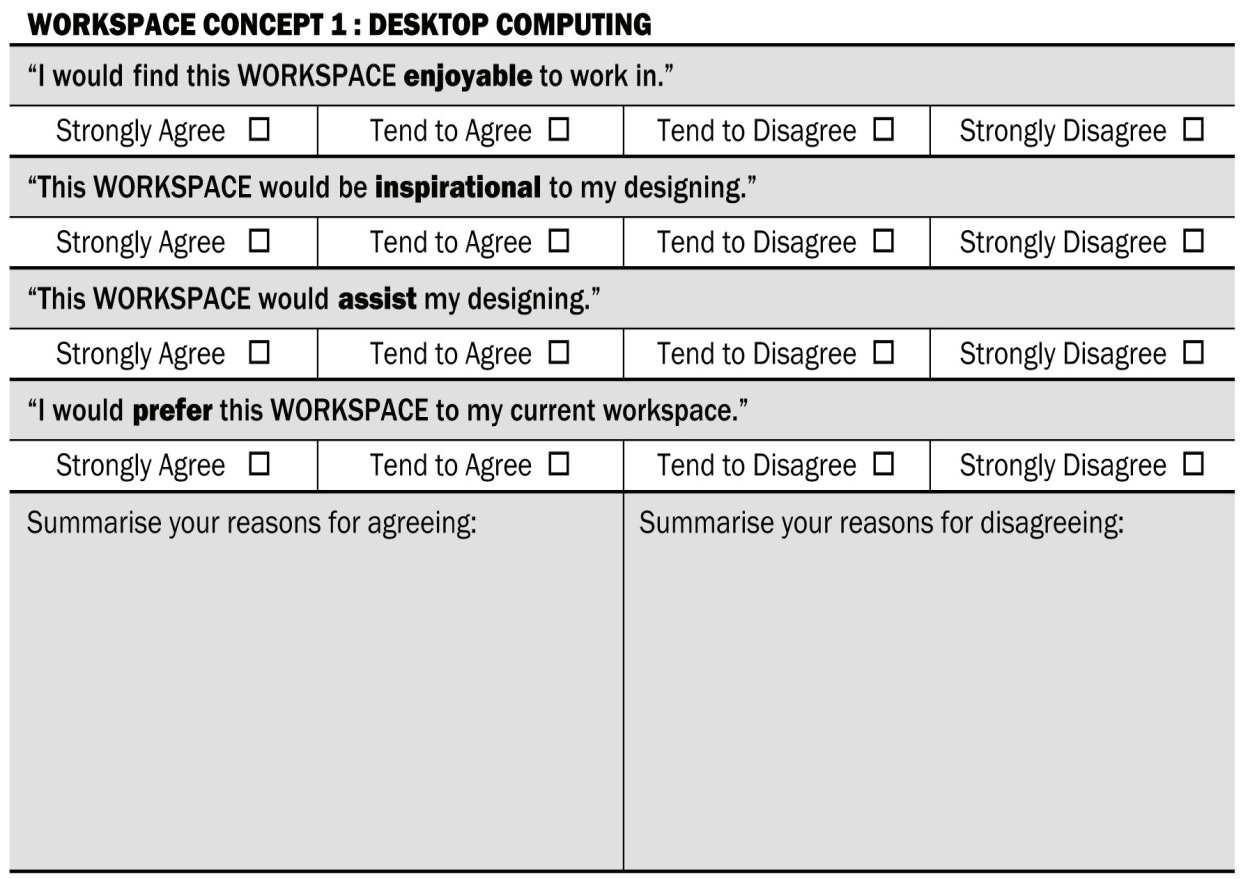

Fig. 6. Questionnaire template 
The Likert scale deliberately lacked a neutral response to encourage the participants to express an opinion. The fourth statement, concerning preferential use, was added to directly assess participants' acceptance of change and overall impressions. This 'preference data' would allow a +ve/-ve correlation to be established against the researcher-constructed 'overall data' (comprising a summation of enjoyment, inspiration and assistance data) and would therefore act as a methodological test. A short summary of the participants' reasons for agreeing or disagreeing with the questionnaire statements was also requested.

A briefing session was held prior to delivery of the questionnaire, to remind the participants of the purposes of the work and the specific aims of the concept evaluation. Written instructions on how to complete the questionnaire were provided. The concepts were presented within a ring-bound portfolio, containing the concept illustrations and text descriptions. A time limit of two hours was set to view the portfolio and complete the questionnaire.

\subsection{Data Analysis Procedure}

The data were analysed by assigning numerical scores to each of the Likert scale grades, so that a quantitative measure of success for each concept could be calculated (Brace, 2004). The data were scored as follows: strongly agree $(+2)$, tend to agree $(+1)$, tend to disagree $(-1)$ and strongly disagree (-2). The score range per criterion was $\pm 20( \pm 2$ maximum/minimum score, 10 participants). The overall score range per concept was \pm 60 ( \pm 20 per criterion, 3 criteria). To aid comparisons and discussion, all data were converted to percentage of score range, creating the following categories.

$$
\begin{gathered}
x \geq+50 \%=\text { participants strongly agreed } \\
+50 \%>x>0 \%=\text { participants tended to agree } \\
-50 \%>x>0 \%=\text { participants tended to disagree } \\
x \geq-50 \%=\text { participants strongly disagreed }
\end{gathered}
$$

The participants' comments regarding their agreement or disagreement with the questionnaire statements were logged verbatim. Keywords were extracted from the comments to develop a deeper understanding of the successes and failures of each concept.

\section{Results}

Figures 7, 8 and 9 show the results of the individual evaluations for enjoyment, inspiration and assistance. Figure 10 presents the results of the overall evaluation, as a summation of the individual evaluations, whilst Figure 11 presents the results of the preference evaluation.

The first general observation to note is that the concepts scored very highly for enjoyment $($ mean $=+61 \%)$ and assistance $($ mean $=+48 \%)$, and reasonably well for inspiration (mean $=$ $+32 \%$ ). Negativity towards any of the concepts was extremely isolated, occurring in only 2 out of a possible 33 evaluations (11 concepts, 3 individual evaluations): WC1 (-20\% for inspiration) and FC6 (-5\% for preference). 


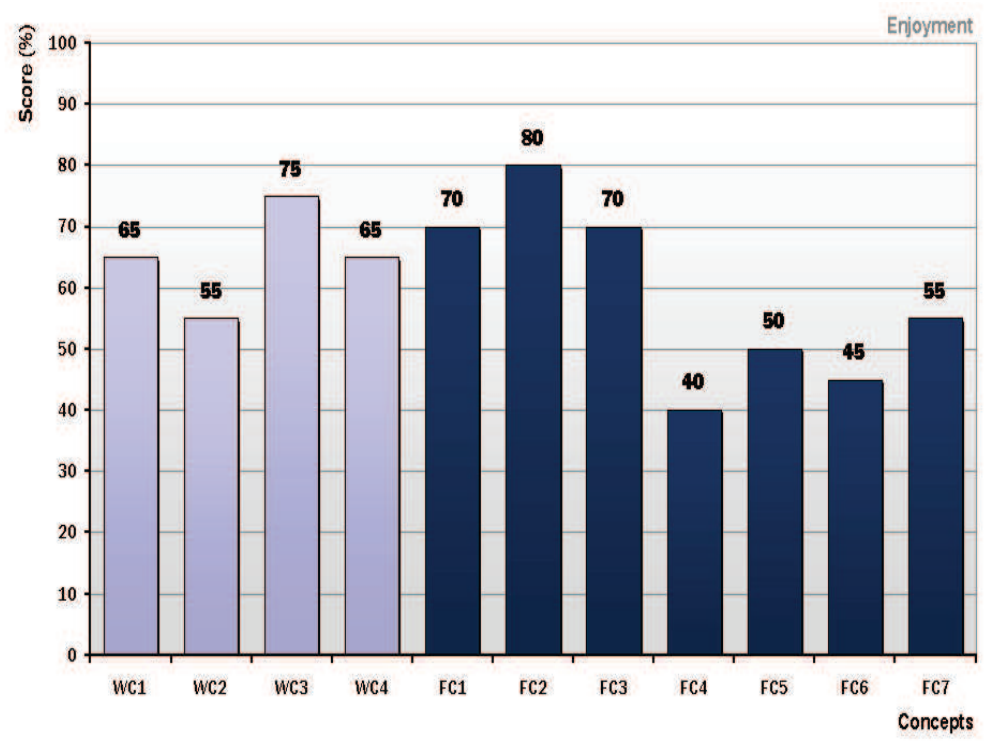

Fig. 7. Results - enjoyment evaluation

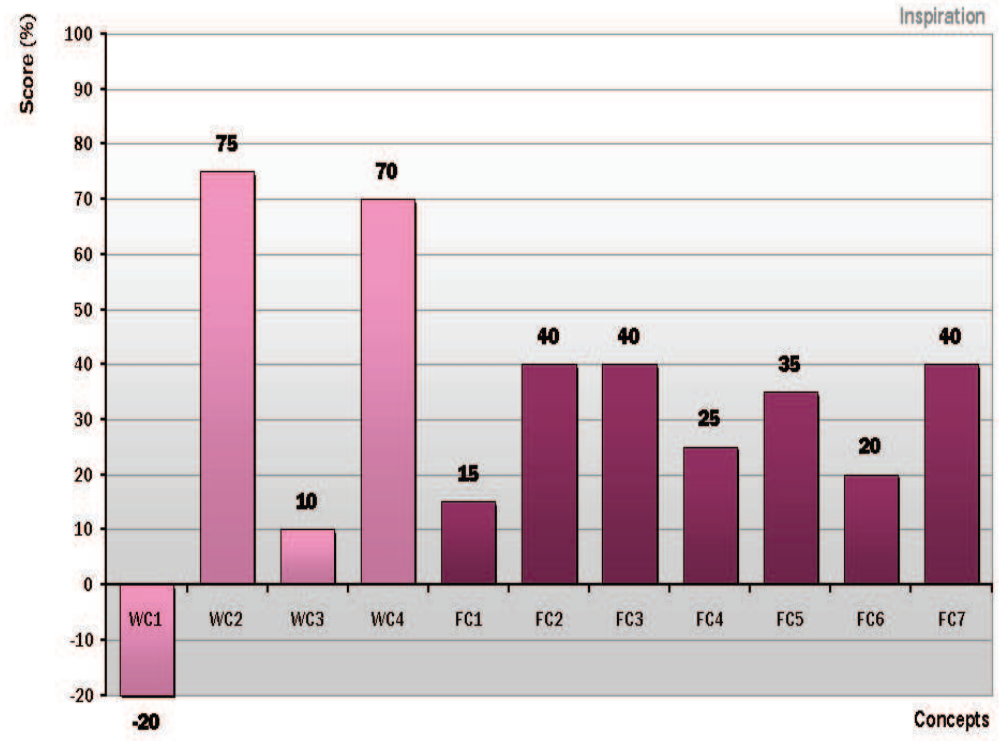

Fig. 8. Results - inspiration evaluation 


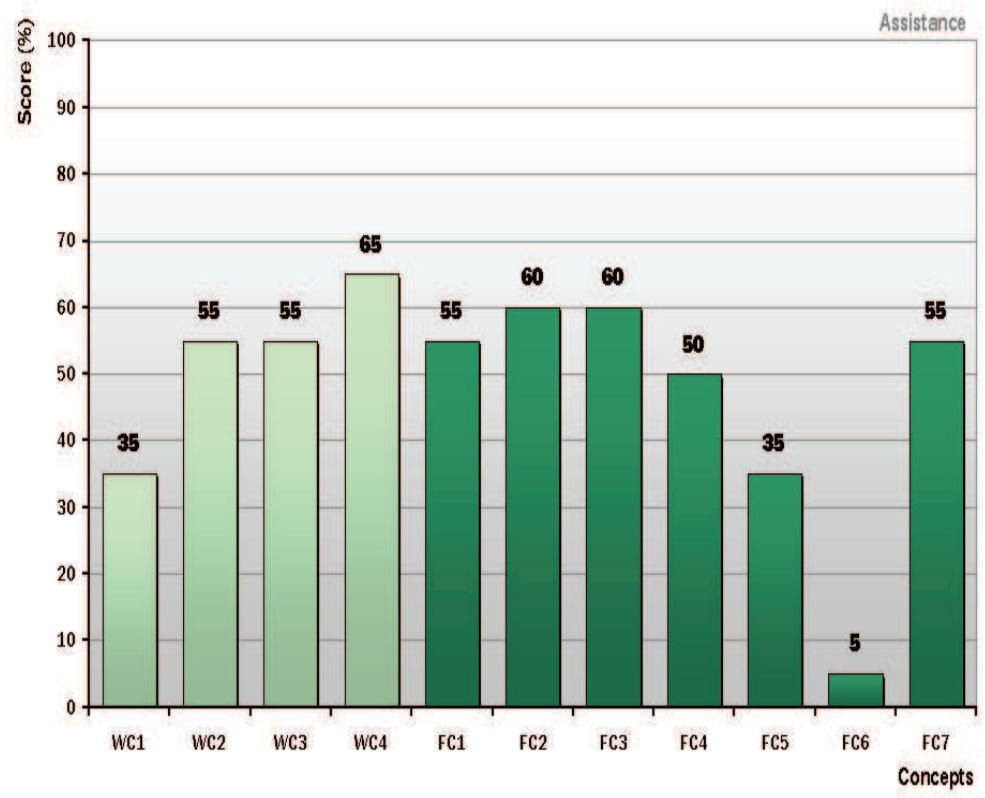

Fig. 9. Results - assistance evaluation

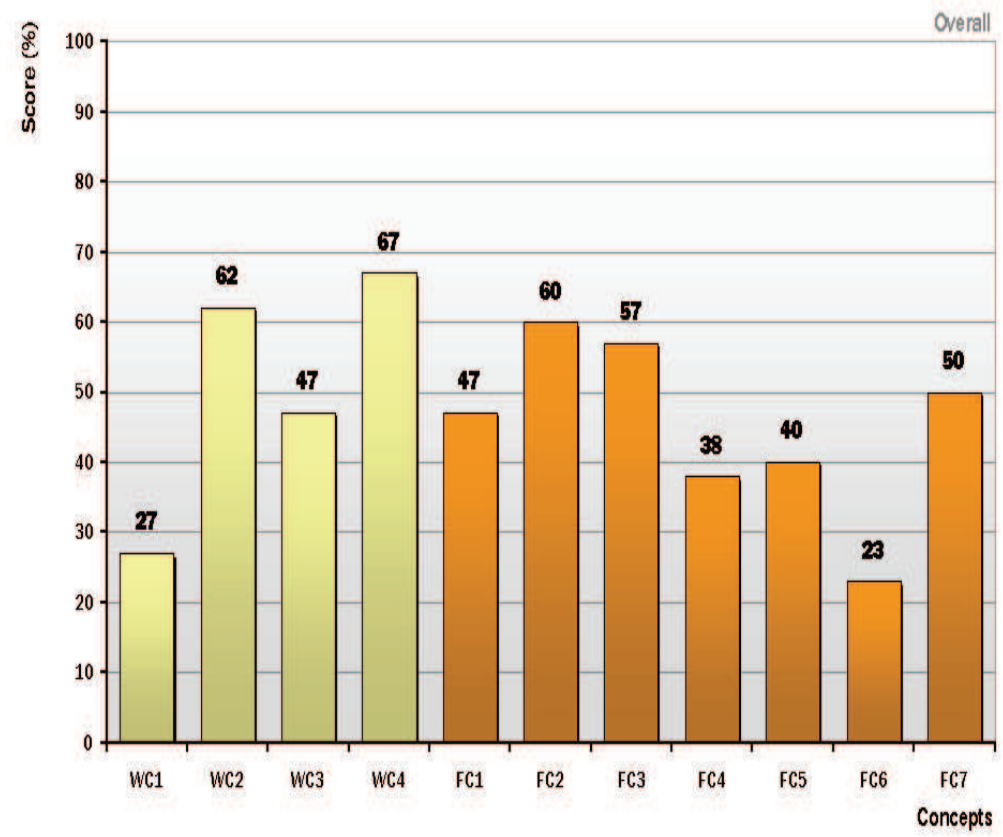

Fig. 10. Results - overall evaluation 


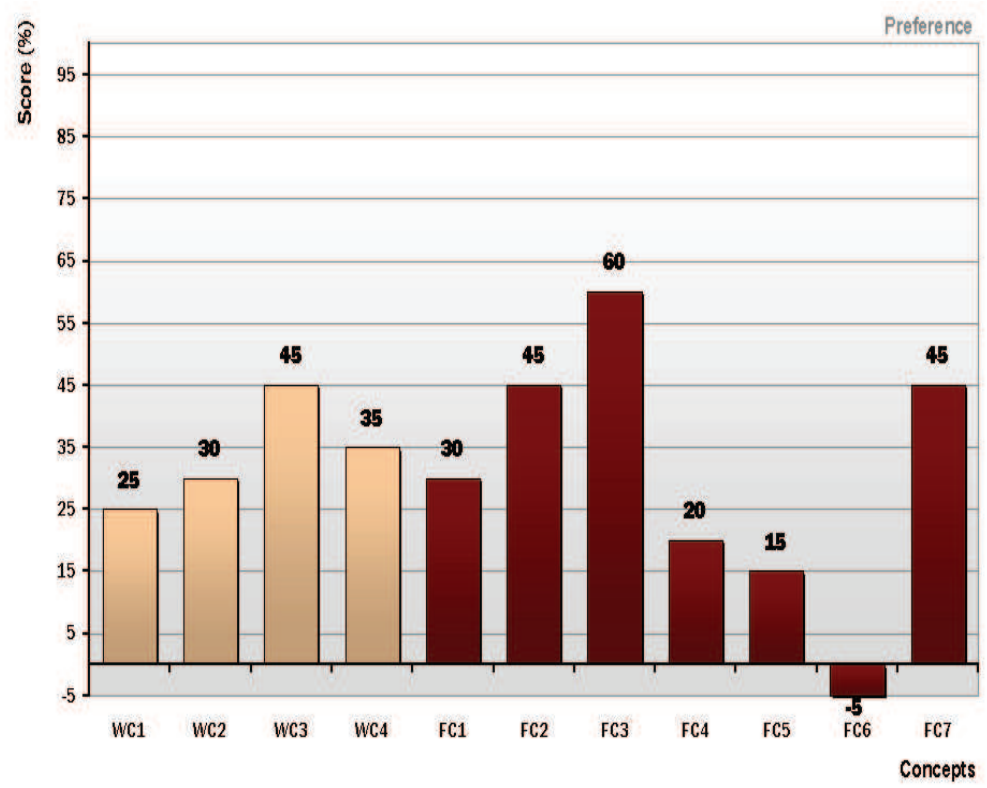

Fig. 11. Results - preference evaluation

\subsection{Enjoyment Evaluation}

Participants strongly agreed that all the concepts would be enjoyable to use, except FC4 $(+40 \%)$ and FC6 $(+45 \%)$, which they only tended to agree would be enjoyable to use. The participants' comments revealed their relative lack of enthusiasm towards FC4 was because the concept was seen as too procedural and slower than alternative methods of digital form creation. For FC6, the participants raised concerns over modelling accuracy, difficulties in describing complex forms and intricate details, usability, and anxiety about talking aloud and making gestures.

\subsection{Inspiration Evaluation}

In general, the participants tended to agree that the presented concepts would be inspirational to their design practice. However, WC2 $(+75 \%)$ and WC4 $(+70 \%)$ were found to be strongly inspirational whereas participants tended to disagree that WC1 $(-20 \%)$ was inspirational. Many aspects of WC2 were praised by the participants: the immersive approach, project interchangeability, concentration and variety of information, high levels of communication, opportunities for teamwork and the ability to visualise ideas full-scale. Similarly high praise was given to WC4, with participants keen on its advanced interactive visualisation, its versatility, the ability to visualise ideas full-scale, the general scope of sensory information that it affords, and its facility for upstream virtual product testing. The participants' negativity towards WC1 was shown in comments referring to the normality of a modernday office, poor interaction between people, few external stimuli and a confined workspace. 


\subsection{Assistance Evaluation}

In general, participants strongly agreed that the concepts would be assistive to their design practice. However, three concepts fell within the tended to agree category: WC1 (+35\%), FC5 $(+35 \%)$ and FC6 (+5\%). The relative lack of enthusiasm for WC1 and FC6 was accounted for in sections 5.1 and 5.2. Comments on FC5 showed the participants to be concerned about accuracy, control, realisation of form details, difficulties in achieving organic forms, and its limitation as a purely deformation-making tool.

\subsection{Overall Evaluation}

Five concepts received overall scores $\geq+50 \%$ : WC2 (+62\%), WC4 (+67\%), FC2 (+60\%), FC3 $(+57 \%)$, and FC7 $(+50 \%)$. These five concepts represent the participants' most favoured potential uses of digital technologies for product form creation. The scores for the remaining six concepts ranged from $+23 \%$ to $+47 \%$, indicating that participants possessed overall support for all eleven concepts in the portfolio, with none of the concepts having overall rejection.

\subsection{Preference Evaluation}

Participants' direct preference data (Figure 11) provided an opportunity for comparison and corroboration with the researcher-derived summed overall score combining enjoyment, inspiration and assistance (Figure 10). The results showed that the rank order of the participants' direct preference scores correlated well with that of the researcher-derived overall scores, although some differences existed in the score values, which will be examined shortly. On the whole, the combination of enjoyment, inspiration and assistance criteria successfully indicated designers' willingness to change from current digital modelling systems to new ones. Their adoption as evaluation criteria was therefore methodologically vindicated.

The participants tended to agree that the concepts were preferable to their present systems $($ mean $=+31 \%)$. Exceptions to this were: FC3, which was considered strongly preferable $(+60 \%)$, and FC6, which was not considered preferable $(-5 \%)$. The participants expressed a strong preference for FC3 because of its full-scale visualisation capabilities, the ability to walk around a projected product and view it from unlimited viewpoints, its 3D sensory feedback, and the attractiveness of appending it to existing CAD systems. The negativity towards FC6 echoed the comments reported previously.

With regard to the workspace concepts, WC1 was rated the least popular under both evaluations and received consistent scores (+27\% overall, $+25 \%$ preference). WC3 was ranked differently under the evaluations (third for overall, first for preference), although it received a consistent score of $+47 \%$ and $+45 \%$ respectively. Some inconsistencies were shown for WC2 and WC4. Although both of these concepts received similar rankings under both evaluations (WC2 either second or third; WC4 either first or second), the scores under the two evaluations differed (WC2 $+62 \%$ overall, $+30 \%$ preference; WC4 $+67 \%$ overall, $+35 \%$ preference). The participants were therefore considerably less enthusiastic about adopting WC2 or WC4 in preference to their current systems. This may be because WC2 and WC4 are technologically quite advanced from current systems and generate some scepticism over their likely success of implementation, despite acknowledged conceptual benefits. 
Cross-comparisons were also made for the form creation concepts. FC1, FC4, FC5 and FC6 were ranked as the lowest four concepts under both evaluations, with FC1 consistently fourth least popular and FC6 consistently the most least popular. The rank order of FC4 and FC5 swapped between the two evaluations. A comparison of the scores received for these four concepts revealed that the preference evaluation was consistently less favourable than the overall evaluation, indicating that despite acknowledging individual benefits within these lowest ranked concepts, the participants were not convinced that overall they would be preferable to their current systems.

In contrast, FC2, FC3 and FC7 were the three highest ranked concepts under both evaluations. FC7 was consistently ranked third, whilst the rank order of FC2 and FC3 swapped between the two evaluations. The scores between the two evaluations of FC2, FC3 and FC7 were reasonably close (FC2 $+60 \%$ overall, $+45 \%$ preference; FC $3+57 \%$ overall, $+60 \%$ preference; FC7 $+50 \%$ overall, $+45 \%$ preference), showing that the participants considered these concepts to be strong, whether assessed as a whole or analysed against individual criteria.

\section{Technological Implications}

Without doubt, the quality of haptic feedback offered by enactive HCI will need to dramatically improve if digital modelling experiences are to become convincing reproductions of designing-and-making and pen-and-paper sketching performed in the physical world. The most valuable technological advances will be those that make it possible to grasp models, to have two-handed control of modelling tools, and that provide a facility to rub one's fingertips and palms across model surfaces to evaluate and adjust for ergonomics, aesthetics and other matters of fitness of form. Haptic devices that are less invasive (e.g. smaller, less heavy) and that have multipoint sensors (e.g. on fingers, thumbs and palms) will be necessary to create more authentic modelling experiences.

Furthermore, any new system should be based on surface modelling technology (e.g. NURBS: non-uniform rational b-spline surfaces), rather than polygon mesh models, to maximise usefulness in downstream manufacturing and analysis applications.

\section{Conclusions}

The chapter has made a case for industrial designers to be served with specialised 3D CAD systems. The thrust of the argument is that a conceptual shift in HCI must take place if industrial design is to be supported by digital tools that properly satisfy industrial designers' needs for sketching and developing product forms. The research demonstrated how current 3D CAD systems fail to fully support these needs, and that recent technological developments in HCI for 3D CAD do not yet offer a fully satisfactory resolution.

Eleven concepts for 3D CAD specialised for industrial design were generated. The concepts were subjected to a first-stage evaluation by expert users, whose assessment was based on various criteria attributable to the $\mathrm{HCI}$ inherent in the concepts. Five concepts were evaluated as especially desirable to users: WC2 'Immersive Room', WC4 'Advanced Wireless Virtual Reality', FC2 'Smart Material', FC3 'Haptic Holographic Representation' and FC7 
'Automated 2D-to-3D Translation'. Overall, users were found to favour HCI providing naturalistic, spontaneous and expressive tools for sketch form creation, specifically away from the paradigm of conventional desktop CAD.

For workspaces, users showed most enthusiasm towards dedicated and customisable workrooms, where an immersive environment can be set and switched seamlessly from project to project. For form creation tools, users showed most enthusiasm towards what may be termed 'virtual workshops' (digital emulations of existent skills in modelling with physical materials) and 'intelligent environments' (supplementing cognitive modelling skills - mental imaging - through assistive digital visualisation, specifically away from the command-led interactions of conventional 3D CAD).

The results of the research justify initiatives for developing prototype and pre-commercial systems for new digital industrial design tools, and for creating R\&D collaborations between specialist HCI and industrial design communities. The next stage for this work is to cooperate with experts in human and computer sciences to develop the favoured concepts to a prototype stage, so that a second-stage evaluation may be performed with a larger and more general group of industrial designers. It will be important to use multimedia techniques and mock-ups to communicate the essence of the concepts in a manner that is more advanced than 2D illustrations and text descriptions. The findings of the second-stage evaluation will be valuable for finalising directions for new commercial systems.

\section{Acknowledgements}

This chapter builds upon an article originally published in Design Studies, entitled 'User evaluation of $\mathrm{HCI}$ concepts for defining product form'.

\section{References}

Arts and Humanities Research Council (2007). Research Review: Practice Led Research in Art, Design and Architecture. Available at:

http://www.ahrc.ac.uk/apply/research/sfi/ahrcsi/research_reviews.asp (accessed 10 May 2008)

Autodesk (2008). Available at: http:/ / www.autodesk.com (accessed 10 May 2008)

Bordegoni, M. \& Cugini, U. (2006) 'Haptic modelling in the conceptual phases of product design', Virtual Reality, Vol. 9, pp. 192-202.

Brace, I. (2004). Questionnaire Design, Kogan Page Ltd., London

Bruner, J. (1966). Towards a theory of instruction, Harvard, Cambridge

European Enactive Network of Excellence (2008). Available at: http:/ / www.enactivenetwork.org (accessed 10 May 2008)

Hanna, R. \& Barber, T. (2001). An inquiry into computers in design: attitudes beforeattitudes after Design Studies, Vol. 22, No. 3, pp. 255-281

Hasdogan, G. (1997). Scenario building as part of the design process, in McGrory, P (ed) The Challenge of Complexity Helsinki, University of Arts and Design, pp. 134-141

Hummels, C. (2000). Gestural Design Tools: Prototypes, Experiments and Scenarios, University of Technology Publications, Delft 
Igarashi, T. \& Hughes, J. (2003). Clothing manipulation, Proceedings of ACM SIGGRAPH 2003, UIST and I3D reprise session, San Diego, p. 67

Jorgensen, D. (1989). Participant Observation - A Methodology for Human Studies, Sage Publications, Newbury Park

Kay, A. (1987). Doing with images makes symbols: communicating with computers, Apple Computer Inc., Cupertino

Kay, A. (1996). 'The early history of SmallTalk' in Programming languages, eds T. Bergin and R. Gibson, ACM Press, New York

Mackay, C.; Cox, T.; Burrows, G. \& Lazzerini, T. (1978). An inventory for the measurement of self-reported stress and arousal Journal of Social and Clinical Psychology, Vol. 17, pp. 283-284

O'Malley, C. \& Fraser, D. (2004). Literature review in learning with tangible technologies, a report for NESTA Futurelab, Available at:

http://www.futurelab.org.uk/resources/publications_reports_articles/literatu re_reviews, (accessed 10 May 2008)

Pedgley, O. \& Wormald, P. (2007). Integration of Design Projects within a PhD. Design Issues. Vol. 23, No. 3, pp. 70-85

Philips Design (1996). Vision of the Future, V\&K Publishing, Blaricum

Piaget, J. (1971). The psychology of intelligence, Routledge and Kegan, Boston

Reachin Technologies A.B. (2008). Available at: http://www.reachin.se (accessed 10 May 2008)

Sener, B. (2004). Enhancing the Form Creation Capabilities of Digital Industrial Design Tools, PhD thesis, Loughborough University, UK

Sener, B. (2007). Rethinking digital industrial design: a mandate for virtual workshops and intelligent environments, Digital Creativity, Vol.18, No.4, pp. 193-206

Sener, B. \& Pedgley, O. (2005). 'Next-generation digital industrial design tools driven by enactive interfaces', Proceedings of Enactive-05 Second International Conference on Enactive Interfaces, Enactive Network, Genoa, Italy [CD-ROM]

Sener, B.; Wormald, P. \& Campbell, I. (2002). Evaluating a haptic modelling system with industrial designers, in Wall, S, Riedel, B, Crossan, A and McGee, M (eds) Proceedings of the 2002 EuroHaptics International Conference Edinburgh, University of Edinburgh, pp 165-170

SensAble Technologies Inc. (2008). Available at: http://www.sensable.com (accessed 10 May 2008)

Shillito, A.; Scali, S. \& Wright, M. (2003). Haptics: for a more experiential quality in a computer interface, Proceedings of the 5th European Academy of Design Conference, 28-30 April 2003, Barcelona, available at: http:/ / www.ub.es/5ead/PDF/9/ShillitoSW.pdf (accessed 10 May 2008)

Tovey, M (2002). Concept design CAD for the automotive industry, Journal of Engineering Design, Vol. 13, pp. 5-18

Ulrich, K. \& Eppinger, S. (1995). Product Design and Development, McGraw-Hill, New York Verplank, B. (2003). Interaction design sketchbook, Available at:

http://ccrma.stanford.edu/courses/250a/lectures/IDSketchbok.pdf, (accessed 10 May 2008) 


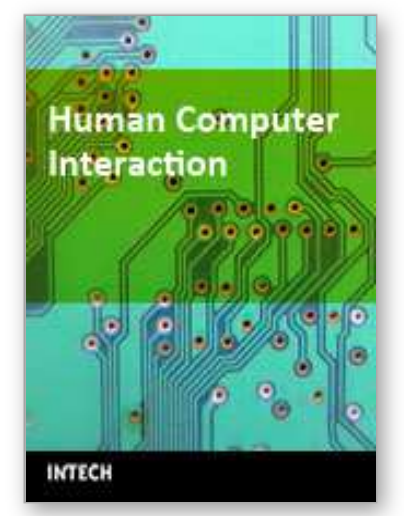

\section{Human Computer Interaction \\ Edited by loannis Pavlidis}

ISBN 978-953-7619-19-0

Hard cover, 522 pages

Publisher InTech

Published online 01, October, 2008

Published in print edition October, 2008

This book includes 23 chapters introducing basic research, advanced developments and applications. The book covers topics such us modeling and practical realization of robotic control for different applications, researching of the problems of stability and robustness, automation in algorithm and program developments with application in speech signal processing and linguistic research, system's applied control, computations, and control theory application in mechanics and electronics.

\section{How to reference}

In order to correctly reference this scholarly work, feel free to copy and paste the following:

Bahar Sener and Owain Pedgley (2008). Novel Multimodal Interaction for Industrial Design, Human Computer Interaction, Ioannis Pavlidis (Ed.), ISBN: 978-953-7619-19-0, InTech, Available from:

http://www.intechopen.com/books/human_computer_interaction/novel_multimodal_interaction_for_industrial_d esign

\section{INTECH}

open science | open minds

\section{InTech Europe}

University Campus STeP Ri

Slavka Krautzeka 83/A

51000 Rijeka, Croatia

Phone: +385 (51) 770447

Fax: +385 (51) 686166

www.intechopen.com

\section{InTech China}

Unit 405, Office Block, Hotel Equatorial Shanghai

No.65, Yan An Road (West), Shanghai, 200040, China

中国上海市延安西路65号上海国际贵都大饭店办公楼 405 单元

Phone: +86-21-62489820

Fax: $+86-21-62489821$ 
(C) 2008 The Author(s). Licensee IntechOpen. This chapter is distributed under the terms of the Creative Commons Attribution-NonCommercialShareAlike-3.0 License, which permits use, distribution and reproduction for non-commercial purposes, provided the original is properly cited and derivative works building on this content are distributed under the same license. 